\title{
DIETARY INTAKES AND IRON STATUS OF VEGETARIAN AND NON- VEGETARIAN CHILDREN IN SELECTED COMMUNITIES IN ACCRA AND CAPE COAST, GHANA
}

\section{Osei-Boadi $\mathrm{K}^{\mathbf{1}}$, Lartey $\mathrm{A}^{*^{2}}$, Marquis $\mathrm{GS}^{3}$ and EK Colecraft ${ }^{4}$}

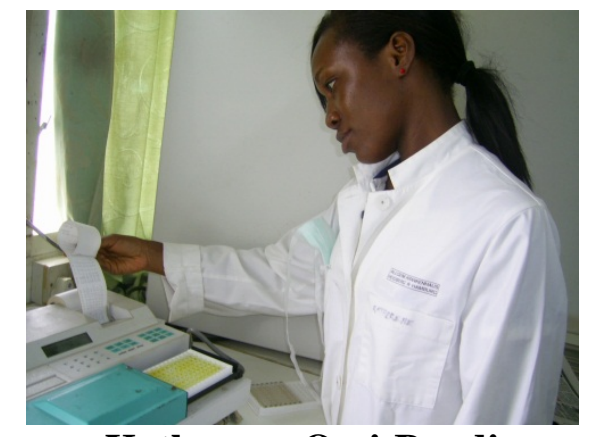

Katherene Osei-Boadi

*Corresponding author email: aalartey@ug.edu.ghor aalartey@hotmail.com

${ }^{1}$ Dept of Nutrition and Food Science, P.O. Box LG 134, University of Ghana, Legon, Ghana.West Africa

${ }^{2}$ Dept of Nutrition and Food Science, P.O. Box LG 134, University of Ghana, Legon, Ghana.West Africa

${ }^{3}$ Centre for Indigenous Peoples' Nutrition and Environment, School of Dietetics and Human Nutrition, Macdonald Campus, McGill University, 21, 111 Lakeshore Rd., Ste. Anne-de-Bellevue, Quebec, Canada H9X 3V9

${ }^{4}$ Dept of Nutrition and Food Science, P.O. Box LG 134, University of Ghana, Legon, Ghana.West Africa 


\section{ABSTRACT}

There is a scarcity of information on dietary intake and iron status of Ghanaian children raised on vegetarian diets. A cross-sectional study design was used to compare the diets and iron status of vegetarian children between the ages of 9 months and 11 years $(n=26)$ with matched controls, non-vegetarian children $(n=26)$ of similar ages and same sex and living within the same communities in Accra and Cape Coast, Ghana. Dietary information was collected using 24-hr food recall and 12-hr home observation. Haemoglobin, plasma ferritin, C-reactive protein, and Transferrin Receptor (TfR) concentrations were determined on finger prick (haemoglobin) and venous blood samples collected during the study. Based on the 24-hr food recall, vegetarian children's diets were devoid of vitamin $B_{12}$ whereas non-vegetarian children's diets were not $(0.0 \pm 0.0 \mathrm{mg}$ vs. $1.5 \pm 1.8 \mathrm{mg}, \mathrm{p}<0.001)$. The dietary intake based on 12-hr home observation showed similar results. However, vegetarians had significantly higher intake of dietary fibre $(17.1 \pm 11.9 \mathrm{~g}$ vs. $8.4 \pm 6.2 \mathrm{~g}, \mathrm{p}=0.002)$, thiamine $(1.1 \pm 0.8 \mathrm{mg}$ vs. $0.5 \pm 0.3 \mathrm{mg}, \mathrm{p}=0.001)$ and vitamin $\mathrm{A}(1702 \pm 1887$ Retinol Equivalent (RE)vs. $671 \pm 691 \mathrm{RE}, \mathrm{p}=0.010$ ) than non-vegetarian children. Dietary diversity based on nine food groups was similar between groups (5.8 \pm 1 .0score). Plasma ferritin was higher for non-vegetarian children compared to the vegetarians (59.2 $\pm 48.2 \mathrm{ng} / \mathrm{mL}$ vs. $34.1 \pm 25.8 \mathrm{ng} / \mathrm{ml}, \mathrm{p}=0.012)$ but there was no group difference in plasma TfR. The prevalence of anaemia was about $25 \%$ in both groups. Typical diets of Ghanaian children lack variety and both vegetarian and nonvegetarian diets are insufficient to support adequate iron status. Iron-rich foods such as meat or supplements are needed. There is urgent need for immediate vitamin $\mathrm{B}_{12}$ supplementation for all vegetarian children and a general need for nutrition education to diversify all children's diets.

Key words: vegetarian, dietary adequacy, micronutrients, children 


\section{INTRODUCTION}

The practice of vegetarianism involving the exclusion of all meat and animal products from the diet may confer some health advantages to adults due to high levels of fibre and low levels of saturated fat. However, for children who are actively growing, a strict vegetarian diet presents a heightened risk of micronutrient deficiencies due to intake of micronutrient-poor diets and the increase in nutrient requirements during childhood. When the diet becomes more restrictive, as in the case of strict vegetarians, it is necessary to carefully select, diversify and plan meals [1,2].Vegetarian diets are more likely to be marginal in nutrients such as iron and vitamin $B_{12}[1,3,4]$ compared to other non-vegetarian diets that contain reasonable amounts of meat, eggs and milk products [1,2].Although the iron content of vegetarian diets is typically similar to that of non-vegetarian diets, the bioavailability of the iron is lower because of the absence of haem-iron and the reduced availability due to the high phytic acid content in plant foods[5]. Iron deficiency is a prevalent nutrient deficiency in the world and affects up to two-thirds of children in most developing countries [6], who typically receive homemade complementary foods that are poor sources of bio-available iron [7]. Since even a high dietary iron intake does not assure optimum bioavailability, it is necessary to promote dietary practices that enhance absorption of iron from plant foods.

Early work on vitamin $\mathrm{B}_{12}$ by Armstrong et al. [8] showed that dietary intake and plasma concentrations of the vitamin were lower in vegetarians than in meat eaters. Dietary vitamin $\mathrm{B}_{12}$ deficiency is not only a problem for vegetarians but also a serious problem in non-vegetarians whose intake of meat is very low due to poverty [9]. Plant food sources do not contain vitamin $B_{12}$, hence the only reliable sources of this vitamin for vegetarians are fortified foods and dietary supplements [10,11].

Meeting nutrient requirements among vegetarian infants and children is challenging and the use of vitamin and mineral supplements or use of foods fortified or enriched with these nutrients may present additional costs to the household. Furthermore, during infancy when nutritional requirement is highest, limited gastric capacity poses a problem. Children fed on vegetarian diets high in fibre, complex carbohydrate and water content may contribute to the risk of having inadequate energy and nutrient intakes $[2,12]$.

In Ghana the practice of vegetarianism among adults and children is uncommon. However, in the last five years, the Ministry of Health (MOH) has introduced the Regenerative Health and Nutrition Program (RHNP), a program that emphasizes among other things the consumption of plant-based diets by households. A nongovernmental organization (African Hebrew Development Agency, AHDA) is working in collaboration with the Ministry of Health to introduce the RHNP among Ghanaians. The RHNP is modelled on the practices of the African Hebrew Israelites of Jerusalem (Dimona, Israel) who are reported to have reduced risk factors of noncommunicable diseases [13]. 
A number of studies in developed countries have demonstrated that children fed on vegetarian diets grow and develop normally when nutrient requirements are met $[1,3]$. However, in sub-Saharan Africa, raising children on vegetarian diets raises concern as access to forms of dietary supplements, typically available to vegetarian populations in developed countries, are lacking. Some households in the Greater Accra and Central regions of Ghana that are affiliated to the African Hebrew Israelite (AHI) community have adopted the regenerative health and nutrition lifestyle for all members of their households, including infants and young children. Considering that vegetarianism is a rare practice for children in Ghana, this study examined whether these households were able to meet their children's requirements on this restrictive diet. This study was carried out to compare the dietary adequacy and iron status of vegetarian children aged 9 months to 11 years old with age-matched non-vegetarian children.

\section{MATERIALSAND METHODS}

\section{Study subjects and recruitment}

The study was conducted from February to November, 2008. Subjects were members of the African Hebrew community who lived in urban areas of Accra and Cape Coast. The African Hebrew community promotes a plant-based diet with the consumption of no animal products (including eggs or dairy products). They also avoid foods with chemical additives. Households with children aged between 9 months and 11 years were identified, through the AHDA office in Accra, Ghana. Using a questionnaire, information was collected on the household's eating habits to confirm the vegetarian practice. A comparison group (control) of children who lived in the same community but who were non-vegetarians were selected from the nearest house to where the vegetarian child lived. So if a vegetarian child lives in house $A$, the closest house that has a child of similar age and sex was approached for inclusion of the child. As much as possible, children were matched for age, sex, and parental socioeconomic status. Vegetarian and non-vegetarian children between the ages of 9 months to11 years, whose parents agreed to participate and provided written informed consent, were recruited for the study.

A total of 28 vegetarian children were identified. One child was excluded because informed consent was not obtained while a 6yearold child (boy) was excluded because he did not practise vegetarianism while living with his non-vegetarian father for the first five years of his life. A total of 26vegetarian children (15 boys and 11 girls) from 17 households were eligible and were recruited for the study. Twenty-six matched non-vegetarians were also recruited from 25 nearby households. For the matched controls, twenty-nine families were contacted; two children were excluded because informed consent was not obtained and another two children were excluded because their parents refused the blood to be drawn for analysis. For inclusion in the vegetarian group, a child must not have eaten any meat, fish, eggs, or any animal source food all of his/her life after the period of exclusive breastfeeding.

The study protocol was approved by the Noguchi Memorial Institute for Medical Research Institutional Review Board, University of Ghana, and the Ghana Health

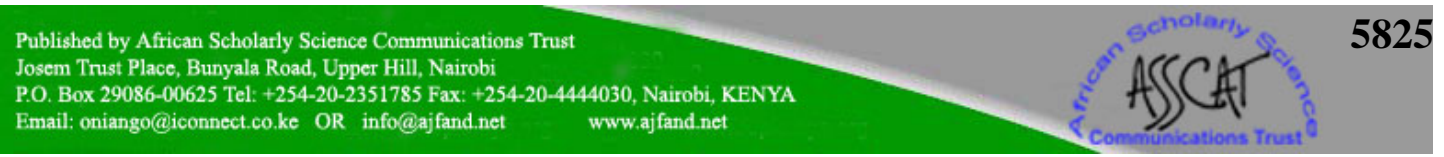


Service Ethical Review Committee. Permission was sought from leaders of AHDA in Ghana. Written informed consent was obtained individually from parents or guardians of the children prior to the commencement of the study.

\section{Sample size}

Haemoglobin concentration was the primary outcome measure. The sample size was determined based on published anaemia prevalence data for a group of United Kingdom vegetarian children (haemoglobin data: $11.8 \pm 0.2 \mathrm{~g} / \mathrm{dl}$ for children aged7-11 years on vegetarian diets and $12.4 \pm 0.2 \mathrm{~g} / \mathrm{dl}$ for children of similar ages on omnivorous diets) [14]. The prevalence of anaemia among the vegetarian children was $47.5 \%$. Using the prevalence of $47.5 \%$, a confidence level of $95 \%$ and a power of 90 , the required sample size per group was 20 children. Assuming a 30\% drop out rate, 26 children per group were recruited.

\section{Data collection}

Most participants received two home visits and completed one laboratory visit during the data collection period. It was not possible to complete the laboratory visit with a few participants and these received an additional home visit. A structured questionnaire was used to collect information on household composition, socioeconomic characteristics, household dietary habits and child feeding practices for the recruited child. The length of time the child had been on the vegetarian diet was verified. Information about child age was obtained from parents and verified with the child's weighing card. Parents were asked to recall all foods eaten by the child in the past 24 hours. Household measures including cups, ladles, spoons and wooden shaped food models were used to assist parents in estimating quantities consumed by the child. Where consumed food was bought outside the home, the same amount was bought by the investigator, when possible from the same vendor, and weighed.

A twelve-hour home observation was used to collect detailed food intake data on a $50 \%$ randomly selected sub-sample of vegetarian and non-vegetarian children. All foods eaten by the child on the day of observation were weighed before and after consumption. From these, the amount consumed was determined. A compact digital scale (CS 2000, Ohaus Corporation, USA) was used for all weighing with a precision of $1 \mathrm{~g}$.

Weights and heights/ lengths for the children were taken by using standard procedures [15]. All measurements were taken in duplicate and the means used in the analysis. Measurements were taken on the first visit to each household.

\section{Blood sample collection and preparation}

About $3 \mathrm{ml}$ of venous blood was drawn from the child through venipuncture into EDTA tubes by a trained phlebotomist either in the home ( $n=24$ in Accra only) or at the laboratory (Clinical Pathology Department of Noguchi Memorial Institute of Medical Research in Accra or Abura Medical Laboratory in Cape Coast). Blood samples collected at home were transported to the laboratory in insulated cold boxes within 3 hours of collection. Plasma was prepared by centrifugation of the blood (5 min. at $2000 \mathrm{rpm}$ ) before storage at $-23^{\circ} \mathrm{C}$. Plasma samples from Cape Coast were 
transported in insulated cold boxes to the Clinical Pathology Department at Noguchi and stored.

\section{Biochemical assessment}

Haemoglobin, plasma ferritin, Transferrin receptor (TfR), and Complement-Reactive Protein concentrations (CRP) were measured for all children. Blood haemoglobin concentration of the children was determined directly in their homes from finger prick blood samples using a portable hemocue (Hemocue AB Angelholm, Sweden). Ferritin and CRP concentrations were determined by Enzyme Linked Immunosorbent Assay (ELISA) technique using ELISA kit (Alpco Diagnostics, USA) while TfR concentrations were assayed in duplicate with the use of commercial ELISA kit (Biovendor- Laboratorni Medicina, USA). Manufacturers' instructions were followed. The units for measurement for each parameter were $\mathrm{g} / \mathrm{dl}, \mathrm{ng} / \mathrm{ml}, \mathrm{mg} / \mathrm{l}$ and $\mu \mathrm{g} / \mathrm{ml}$ for haemoglobin, ferritin, CRP and TfR, respectively.

\section{Quality control measures}

To confirm the dietary practice of the vegetarian children, verbal interviews were conducted with the parents, neighbours, older siblings and in a few cases teachers of the children. Parents of vegetarian children prepared food for their children to take to school. They did not give their children any money to purchase food when going to school and had informed teachers about their children's dietary practice so the teachers could keep an eye on them while in school. The vegetarian practice was confirmed for all children.

\section{DATA ANALYSIS}

\section{Dietary, biochemical, and anthropometric outcomes}

Dietary intake data from the 24-hour recall and 12-hour home observation were converted into energy and nutrients using Ghana nutrient database [16,17]. Based on the dietary data obtained from the 24-hour recall (which included data on all children) a food diversity score was calculated based on the sum of nine food groups. This study used a modified food diversity score adapted from Savy et al.[18] that included:(i)cereals; (ii) roots/tubers, (iii) pulses and nuts, (iv)green leafy vegetables, (v) other vegetables, (vi) fruits, (vii) fats and oils; (viii) fish and sea foods; meat/poultry/eggs, milk/dairy products; (ix) drinks/beverages. If the food consumed by a child had constituents from any of the nine food groups, they were assigned a score of one (1) for that particular food group that day. A score of zero (0) was assigned if the child did not consume any food item from a given food group. A child could, therefore, have a maximum score of 9.

The INACG/WHO/UNICEF cut offs for anaemia ( $<11.0 \mathrm{~g} / \mathrm{dl}$ for $0.5-5$ year olds and $<11.5 \mathrm{~g} / \mathrm{dl}$ for $>5-11$ year old) were employed in this study [19]. Iron deficiency anaemia was defined as a combination of ferritin $<15 \mathrm{ng} / \mathrm{ml}$ and haemoglobin $<11.5 \mathrm{~g} / \mathrm{dl}$. The presence of a sub-clinical infection was indicated by a CRP $>10 \mathrm{mg} /$ L. 
Children's weights and heights were converted to weight-for-age, weight-for-height and height-for-age z-scores using the WHO standards [20] and WHO reference 2007 SPSS macro package for children aged 0-59 mo and 5-19 years [21]. The mean WAZ, HAZ and WHZ were compared between the two groups of children.

Data entry and analysis were completed using SPSS version 11.5. The means and standard deviations of continuous variables were determined. For categorical variables, proportions were reported. Student's t-test for continuous variables and Pearson's Chi square for categorical variables were used to compare the indicators of socioeconomic status and household characteristics, biochemical, anthropometry, and dietary values between the vegetarian and non-vegetarian children.

\section{RESULTS}

\section{Caregiver, household and subject characteristics}

There was no significant difference between the vegetarian and non-vegetarian households in terms of years of caregiver education, age or marital status (Table 1).Source of drinking water differed; most (68\%) non-vegetarian caregivers used piped water whereas vegetarian families (94.9\%) purchased their drinking water in sachets.

By design, age and sex distribution of vegetarian and non-vegetarian controls were not significantly different (Table 2). All the children in both groups had been breastfed during infancy. At the time of interview, only five children were still breastfeeding. Duration of exclusive breastfeeding and number of children given colostrums were not significantly different between the two groups. However, nonvegetarian children were breastfed significantly longer than vegetarian children (16.6 \pm 6.0 months versus $13.3 \pm 4.7$ months, $\mathrm{p}=0.040$ ).

\section{Dietary intakes of vegetarian and non-vegetarian children}

The energy and other nutrient intakes of vegetarian and non-vegetarian children were based on one day 24-hour dietary recall (Table 3). Vegetarian children had significantly higher mean intakes of dietary fibre $(p=0.002)$, thiamine $(p=0.001)$ and vitamin $A(p=0.01)$ than non-vegetarian children but lower vitamins $B_{12}(p<0.001)$ as vegetarian children's diets were devoid of this vitamin. All non-vegetarian children did not meet their requirement for fibre and over $70 \%$ of children in both groups did not meet their requirement for calcium or riboflavin (Table 4).

Based on the dietary intake data from the 12- hour home observation, the mean intakes of energy and several other nutrients were similar among vegetarian and nonvegetarian children except for vitamin $\mathrm{B}_{12}$ which was completely absent from the diet of vegetarian children(Table5).

\section{Dietary diversity of vegetarian and non-vegetarian children's diets}

The dietary diversity pattern of vegetarian and non-vegetarian children based on the 24-hour dietary recall showed that more than $90 \%$ of children in both groups consumed foods from cereals, other vegetables (non-green leafy vegetables) and fats and oil food groups. Consumption of foods from the green leafy vegetables and fruit 
groups was significantly higher in vegetarian children than in non-vegetarian controls $(p<0.01)$. By definition, none of the vegetarian children consumed foods from the Animal Source Food (ASF) group. On average, most children ate from five food groups, namely cereals, pulses and nuts, other vegetables, fats and oils and fruits but for the non-vegetarian children it was ASF instead of fruits. There was no significant group difference between the mean food diversity score of children when ASF was counted and when ASF was not counted (Table 6).

\section{Nutritional indicators}

Haemoglobin and plasma transferrin receptor concentrations were not significantly ( $>$ 0.05) different between the two groups (Table 7). However, non-vegetarian children had significantly $(p=0.012)$ higher iron stores with almost 2-fold higher plasma ferritin levels. The prevalence of iron deficiency anaemia, anaemia (from all causes), and the presence of sub-clinical infection were similarly distributed between groups. The two groups did not differ in anthropometric indicators of nutritional status (Table 2).

\section{DISCUSSION}

The recent practice of vegetarianism among some households in Ghana provided the opportunity to compare the dietary intakes of children raised as vegetarians with those of children from non-vegetarian households. The study results suggest that irrespective of dietary practices, there are indications of nutritional deficiencies in the diets of both vegetarian and non-vegetarian children in Accra and Cape Coast, Ghana. The higher vitamin A intakes of the vegetarians may be attributable to consumption of more green leafy vegetables and yellow fruits (.such as mango). Rich food sources of vitamin A include liver and fish liver oils; however, precursors of vitamin A also occur in plants and oils such as pro-vitamin A carotenoids. Dwyer et al.[3] reported higher intakes of vitamin A and thiamine in 39 vegetarian children from 24-hour recall dietary histories in the United States. Sanders and Reddy [1] also reported higher intakes of vitamin A, thiamine and dietary fibre in vegetarian children aged 613 years as compared to omnivorous children aged 7-12 years in the United Kingdom. Plant-based diets are high in dietary fibre and thus probably explain the high intakes observed among the vegetarian children. The finding that vitamin $\mathrm{B}_{12}$ intake in vegetarian children was non-existent (none was recorded for both the 12-hour home observation and 24-hour dietary recall) is consistent with what has been published in literature. Dwyer et al.[3] reported normal mean intakes of vitamin $\mathrm{B}_{12}$ in a group of 39 preschool children in the United States consuming different types of vegetarian diets (small amounts of fish and other animal foods, milk / eggs, or no animal source food). However, vitamin $B_{12}$ levels were found to be lowest in vegan children. Considering that vitamin $\mathrm{B}_{12}$ is found in significant and consistent amounts only in Animal Source Foods (ASF), and since the vegetarian children did not consume any ASF or foods fortified with the vitamin, the result obtained was not surprising.

Attention must be given to ways in which vitamin $\mathrm{B}_{12}$ can be incorporated into the diets of vegetarians as well as non-vegetarian children among whom $50 \%$ had vitamin $\mathrm{B}_{12}$ intake levels below the Dietary Reference Intake (DRI). The low intake of ASF

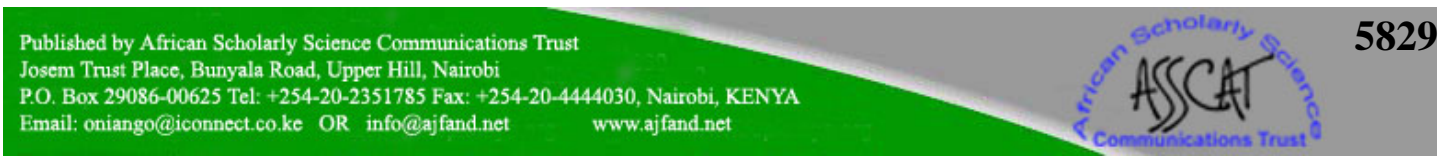


among non-vegetarian Ghanaian children increases the risk of vitamin $\mathrm{B}_{12}$ deficiency. Attention needs to be directed to the quality of diet of both vegetarian and nonvegetarian Ghanaian children to prevent vitamin $B_{12}$ deficiency. Deficiency of this vitamin may lead to the slow and progressive degeneration of the spinal cord and brain without showing clinical deficiency symptoms [4]. The risk of vitamin $\mathrm{B}_{12}$ deficiency is higher in children than in adults because children have smaller nutrient stores at a critical development stage. A number of studies in developed countries have reported cases of children with combined vitamin $\mathrm{B}_{12}$ deficiency and neurological symptoms and occasionally brain damage [22, 23]. Although the study did not determine plasma vitamin $B_{12}$ levels in the children, the very low intake of the vitamin is likely to increase the risk of deficiency. Vitamin $\mathrm{B}_{12}$ deficiency has also been linked with an increased risk of development of megaloblastic anaemia [24]. The use of foods fortified with vitamin $B_{12}$ and supplements containing vitamin $B_{12}$ is necessary for vegetarian children. For non-vegetarian children, increasing the ASF content of the diet will help to prevent vitamin $\mathrm{B}_{12}$ deficiency.

From both the 24-hour recall and 12-hour home observation, mean intakes of dietary iron appeared adequate for children in both groups. Among the non-vegetarian children, ASF contributed only $11 \%$ of the total iron intake (result not shown). Most of the dietary iron intake of both groups of children came from plant sources. This raises the concern about bioavailability as the presence of inhibitors such as phytates and polyphenols found in plants, may inhibit the absorption of non-haem iron from plant foods. About 70, 90 and $40 \%$ of children did not meet the requirements for riboflavin, calcium and zinc, respectively. In addition, about $65 \%$ of both groups of children did not meet their energy requirements. These results suggest that both vegetarian and non-vegetarian Ghanaian diets are inadequate. Both diets need substantial improvement to meet the growing needs of children.

Consumption of fruits and green leafy vegetables was significantly higher in vegetarian children than in non-vegetarian children. Dagnelie et al.[4] also reported higher intakes of green leafy vegetables in vegetarian children than non-vegetarian Dutch children. This is a desirable practice considering the confirmed benefits of consuming fruits and vegetables in combating non-communicable diseases. However, these vegetables should be eaten together with vitamin C-rich foods to improve the bioavailability of non-heme iron. As expected, vegetarian children did not consume any ASF foods. Three of the non-vegetarian children did not consume any ASF at all. Less than $12 \%$ of dietary iron was contributed by ASF in non-vegetarian children while less than $45 \%$ of dietary protein was contributed by ASF. Cereals, fats and oils and other vegetables (such as pepper and tomatoes) were the foods consumed by almost all the children. Lack of dietary diversity is a problem among poor populations in the developing world, where diets are based predominantly on starchy staples, often with little or no animal products and only seasonal fruits and vegetables.

The mean dietary diversity score was similar for both groups of children. Although the diets of the vegetarian children contributed more fruits and vegetables than that of the non-vegetarian children, this did not increase the total diversity of their diet beyond that of the non-vegetarian children, Similarly, the diets of the nonvegetarian children which included ASF did not increase the total diversity of the diet

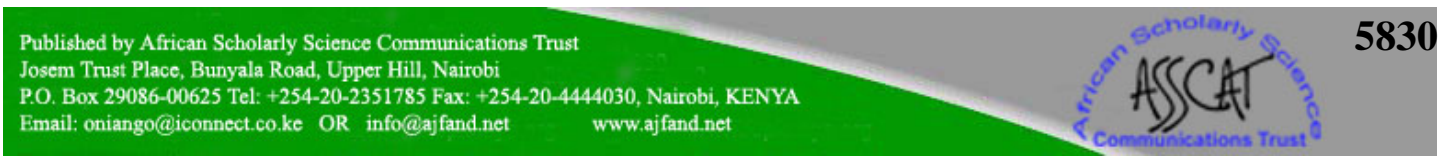


beyond that of the vegetarian children. Both fruit and vegetable food group and ASF group must be present in the diet to improve diversity. Marquis et al.[25] reported low ASF intake and low diversity in the diets of children in food insecure households in three ecological zones (Winneba, Techiman and Navrongo) of Ghana. Animal source foods have the potential to provide enough calcium, iron and zinc for infants [26]. Efforts to improve the quality and diversity of diets of Ghanaian children should include the promotion of the consumption of ASF as well as fruits and vegetables. For children on vegetarian diets, the use of fortified foods may address these deficiencies.

\section{Biochemical assessment of iron status}

Plasma ferritin, as an indicator of body iron stores, has limitations. This is because ferritin is an acute phase protein and the concentration in the plasma becomes elevated in the event of infections or inflammation. When iron deficiency co-exists with infections or inflammation there is the tendency to increase detection of false negatives (that is individuals who are iron deficient but have high ferritin concentrations depicting normal iron stores). To eliminate this possibility, C-reactive protein (CRP), a marker for infections was measured. A total of eight vegetarian children (30.8\%) and seven non-vegetarian children (26.9\%) had elevated CRP (> $10 \mathrm{mg} / \mathrm{L}$ ) so their values were not included in the ferritin analysis. Non-vegetarian children had significantly ( $\mathrm{p}=0.012$ ) higher mean ferritin concentrations than vegetarian children. The better iron stores observed in non-vegetarian children may be attributed to the consumption of ASF, however little. The ASF may have increased the absorption of iron and other minerals and hence contribute to better iron stores. Although the mean intake of dietary iron of children in both groups was not significantly different, the bioavailability of iron from plant sources is much lower than that from animal source foods [27]. This may have accounted for the lower ferritin stores observed in the vegetarian children compared to the non-vegetarian children. Studies on iron status have consistently shown that serum ferritin is lower in vegetarians than in non-vegetarians, although haemoglobin levels are similar or slightly lower in vegetarians than in non-vegetarians [28]. About a quarter of children in both groups were anaemic. Two (11.1\%) vegetarian children and 3 (15.8\%) nonvegetarian children had iron deficiency while only one child each from both groups had iron deficiency anaemia (a combination of iron deficiency and anaemia). It is likely that factors other than dietary iron deficiency alone may have contributed to the relatively high level of anaemia among both groups of children. Some of these factors may be infections (worm infestations), malaria, and sickle cell disease [29]. Other factors such as deficiencies of vitamins $B_{12}$ and $B_{6}$ may be problematic [27]. A study of women of child-bearing age in China showed that vitamin $\mathrm{B}_{6}$ contributed to prevalence of anaemia [30]. The lack of significant difference between haemoglobin and TfR concentrations of children in this study strengthens the fact that the dietary intakes of children in both groups were similar.

Iron deficiency and iron deficiency anaemia adversely affect the cognitive development and growth of infants, pre-schoolers and school-aged children. For this, reason, the high anaemia prevalence found in children in both groups raises concern. Early detection and treatment of iron deficiency are important as prolonged deficiency could lead to neurological effects of lasting consequences. One such approach is the 


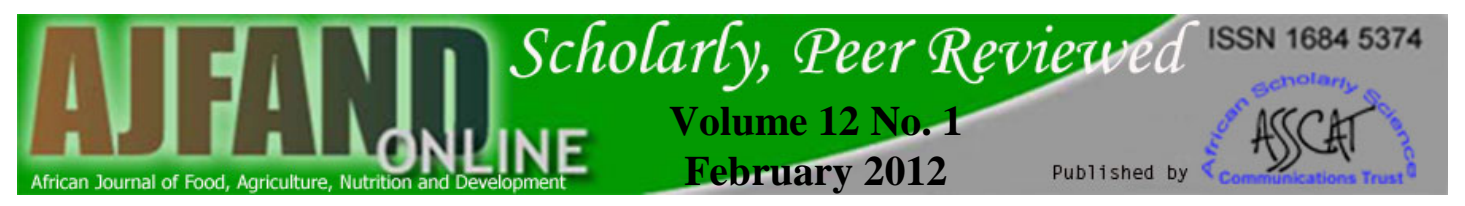

haematological screening with the biochemical marker ferritin which is reported to be the cornerstone to identify iron deficiency in the early stage of compromised iron status [31].

In conclusion, the findings confirm that children fed on vegetarian diets are at a risk of vitamin $\mathrm{B}_{12}$ deficiency. Typical non-vegetarian Ghanaian diets for children were also deficient in animal source foods and, therefore, have implications (poor growth outcomes) for the maintenance of a good nutritional status. Both the vegetarian and non-vegetarian diets were insufficient to support adequate iron status of children given that about $25 \%$ of children from both groups were anaemic. Efforts to improve the quality of diets of Ghanaian children should include the addition of more ASF to children's diets. Although, not recommended, if children must be raised on vegetarian diets, their caregivers need to be made aware of the known risks of such diets and provided with education to carefully select dietary ingredients that will add variety to the diet.

\section{ACKNOWLEDGMENTS}

The authors are grateful to the African Hebrew Development Agency for approval to work with their group, as well as the households and the caregivers for their willingness to participate in the study. We also thank the research assistants who assisted with the data collection. The authors are thankful to Noguchi Memorial Institute for Medical Research, Koforidua Regional Hospital (Madam Francisca Dzata) and Abora Medical Laboratories in Cape Coast (Mr. Marmon) for use of their laboratories for blood collection, processing and analysis. Katherene Osei-Boadi is grateful to the Global livestock CRSP for a Jim Ellis scholarship. 
Table 1: Demographic and household characteristics of caregivers of vegetarian and non-vegetarian children in Accra and Cape Coast, Ghana ${ }^{1}$

\begin{tabular}{|c|c|c|c|}
\hline & $\begin{array}{l}\text { Vegetarians } \\
(\mathrm{n}=17)\end{array}$ & $\begin{array}{c}\text { Non-vegetarians } \\
(n=25)\end{array}$ & P-value $^{2}$ \\
\hline \multicolumn{4}{|l|}{ Characteristic } \\
\hline \multicolumn{4}{|l|}{ Caregiver } \\
\hline Education(y) & $11.0 \pm 2.8$ & $11.0 \pm 4.5$ & 0.980 \\
\hline Age (y) & $31.3 \pm 8.4$ & $32.1 \pm 9.4$ & 0.770 \\
\hline \multicolumn{4}{|l|}{ Marital status } \\
\hline Married & $13(76.5)$ & $20(80.0)$ & \\
\hline Not married & $4(23.6)$ & $5(20.0)$ & 0.780 \\
\hline \multicolumn{4}{|l|}{ Religion } \\
\hline Christian & 0 & $23(92.0)$ & \\
\hline Muslim & 0 & $2(8.0)$ & \\
\hline African Hebrew Israelite & $17(100.0)$ & 0 & \\
\hline \multicolumn{4}{|l|}{ Household } \\
\hline \multicolumn{4}{|l|}{ Source of drinking $\mathrm{H}_{2} \mathrm{O}$} \\
\hline Piped & $1(5.9)$ & $17(68.0)$ & $<0.001^{2}$ \\
\hline Sachet & $16(94.9)$ & $8(32.0)$ & \\
\hline \multicolumn{4}{|l|}{ Toilet facility } \\
\hline Flush toilet & $9(52.9)$ & $12(48)$ & 0.420 \\
\hline Pit latrine & $6(35.3)$ & $6(24)$ & \\
\hline Other ${ }^{3}$ & $2(11.8)$ & $7(28)$ & \\
\hline \multicolumn{4}{|l|}{ Household size } \\
\hline $1-3$ & 6 (35.3) & $2(8.0)$ & 0.090 \\
\hline $4-6$ & $10(58.8)$ & $21(84.0)$ & \\
\hline Above 6 & $1(5.9)$ & $2(8.0)$ & \\
\hline Money on food/wk (Ghథ $)^{4}$ & $31.1 \pm 20.2$ & $35.4 \pm 25.2$ & 0.560 \\
\hline \multicolumn{4}{|c|}{${ }^{1}$ Data shown as mean + SD or $n(\%)$} \\
\hline $\begin{array}{l}2 \text { Significance associated wit } \\
\text { and Student's t-test for conti } \\
{ }^{3} \text { None, bucket/pan } \\
{ }^{4} \text { US } \$=1.05 \text { Ghana } \mathbb{~} \text { in } 2\end{array}$ & $\begin{array}{l}\text { arson's Chi sc } \\
\text { Is variables }\end{array}$ & statistics for categ & variables \\
\hline
\end{tabular}




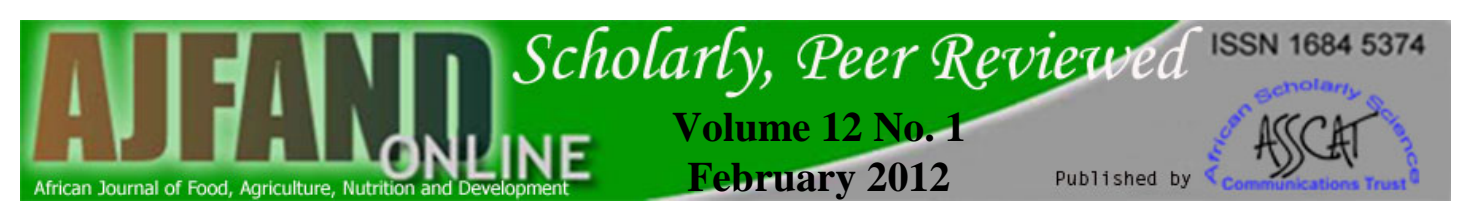

Table 2: Background information and child feeding practises of vegetarian and non-vegetarian children in Accra and Cape Coast, Ghana ${ }^{1}$

\begin{tabular}{|c|c|c|c|}
\hline Child characteristic & $\begin{array}{l}\text { Vegetarians } \\
(\mathrm{n}=26)\end{array}$ & $\begin{array}{c}\text { Non-vegetarians } \\
(\mathrm{n}=26)\end{array}$ & P-value $^{2}$ \\
\hline Age of child (mo) & $55.0 \pm 35.3$ & $58.0 \pm 34.4$ & 0.825 \\
\hline \multicolumn{4}{|l|}{ Sex of child } \\
\hline Male & $15(57.7)$ & $15(57.7)$ & 1.000 \\
\hline Female & $11(42.3)$ & $11(42.3)$ & \\
\hline HAZ & $\begin{array}{r}-0.37 \pm 0.86 \\
(\mathrm{n}=26)\end{array}$ & $\begin{array}{r}-0.44 \pm 0.96 \\
(\mathrm{n}=26)\end{array}$ & 0.590 \\
\hline WAZ & $\begin{array}{r}-0.14 \pm 1.20 \\
(\mathrm{n}=24)\end{array}$ & $\begin{array}{r}-0.32 \pm 0.76 \\
(\mathrm{n}=24)\end{array}$ & 0.560 \\
\hline WHZ & $\begin{array}{r}0.17 \pm 1.50 \\
(\mathrm{n}=16)\end{array}$ & $\begin{array}{r}0.09 \pm 0.69 \\
(\mathrm{n}=15)\end{array}$ & 0.850 \\
\hline
\end{tabular}

\section{Feeding practices}

Ever breastfed

$26(100.0) \quad 26(100.0)$

Still breastfeeding

$$
3(11.5)
$$

$$
2(7.7)
$$

Duration of exclusive

BF
1-3 mo
4-5 mo
$6 \mathrm{mo}$

Colostrum given

Duration of BF (mo)

$\begin{array}{lr}5(19.1) & 6(23.1) \\ 6(23.1) & 2(7.7) \\ 7(26.9) & 9(34.6)\end{array}$

$24(92.3) \quad 26(100.0)$

$13.3 \pm 4.7 \quad 16.6 \pm 6.0$

${ }^{1}$ Values shown as mean \pm standard deviation or $\mathrm{n}(\%)$

${ }^{2}$ Chi-square test was used to test differences between proportions; Student's t-test was used to compare means 


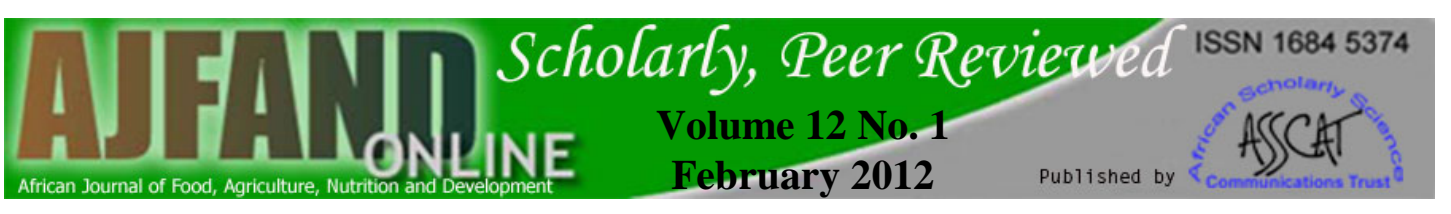

Table 3: Energy and nutrient intakes of vegetarian children from Accra and Cape Coast compared with non-vegetarian controls based on a 24-hour recall ${ }^{1}$

\begin{tabular}{lrrr}
\hline Nutrient & $\begin{array}{r}\text { Vegetarians } \\
(\mathbf{n = 2 6})\end{array}$ & $\begin{array}{r}\text { Non-vegetarians } \\
(\mathbf{n = 2 6 )}\end{array}$ & P-value $^{2}$ \\
\hline Energy (kcal) & $1262.5 \pm 488.2$ & $1308.6 \pm 471.4$ & 0.730 \\
Protein (g) & $30.9 \pm 16.3$ & $35.9 \pm 18.1$ & 0.310 \\
Dietary fibre (g) & $17.1 \pm 11.9$ & $8.4 \pm 6.2$ & 0.002 \\
Thiamin (mg) & $1.1 \pm 0.8$ & $0.5 \pm 0.3$ & 0.001 \\
Riboflavin (mg) & $0.6 \pm 0.4$ & $0.5 \pm 0.3$ & 0.440 \\
Vitamin B ${ }_{12}$ (mg) & $0.0 \pm 0.0$ & $1.5 \pm 1.8$ & $<0.001$ \\
Vitamin A (RE) & $1702.1 \pm 1887.1$ & $671.2 \pm 690.9$ & 0.010 \\
Vitamin C (mg) & $99.9 \pm 75.1$ & $64.3 \pm 56.1$ & 0.060 \\
Calcium (mg) & $273.7 \pm 121.1$ & $339.5 \pm 170.9$ & 0.120 \\
Iron (mg) & $12.5 \pm 6.0$ & $12.7 \pm 5.8$ & 0.880 \\
Zinc (mg) & $4.9 \pm 3.0$ & $5.4 \pm 2.6$ & 0.600 \\
\hline $\begin{array}{l}{ }^{1} \text { Values shown as mean } \pm \text { SD } \\
{ }^{2} \text { Differences tested with Student’s t-test }\end{array}$ & &
\end{tabular}




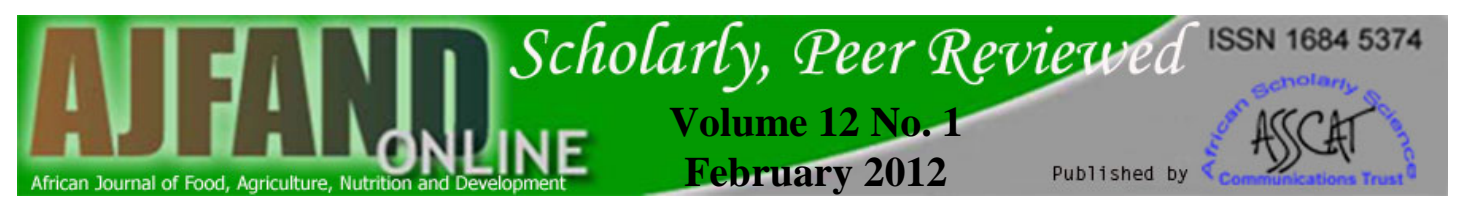

Table 4: Percentage of vegetarian and non-vegetarian children from Accra and Cape Coast with dietary intakes below Dietary Reference Intakes, based on one 24 hour recall $^{1}$

\begin{tabular}{|c|c|c|c|}
\hline Nutrient & $\begin{array}{r}\text { Vegetarians } \\
(n=26)\end{array}$ & $\begin{array}{r}\text { Non-vegetarians } \\
(n=26)\end{array}$ & P-value $^{2}$ \\
\hline Energy & $19(73.1)$ & $17(65.4)$ & 0.550 \\
\hline Protein & $4(15.4)$ & $1(3.8)$ & 0.160 \\
\hline Dietary fibre & 20 (76.9) & $26(100.0)$ & 0.004 \\
\hline Thiamine & 7 (26.9) & $16(61.5)$ & 0.010 \\
\hline Riboflavin & 18 (69.2) & $19(73.1)$ & 0.760 \\
\hline Vitamin $\mathrm{B}_{12}$ & $26(100.0)$ & $13(50.0)$ & $<0.001$ \\
\hline Vitamin A & $8(30.8)$ & 14 (53.8) & 0.090 \\
\hline Vitamin C & 3 (11.5) & 5 (19.2) & 0.440 \\
\hline Calcium & $26(100.0)$ & 25 (96.2) & 0.310 \\
\hline Iron & 5 (19.2) & $6(23.1)$ & 0.730 \\
\hline Zinc & $13(50.0)$ & $10(38.5)$ & 0.400 \\
\hline
\end{tabular}




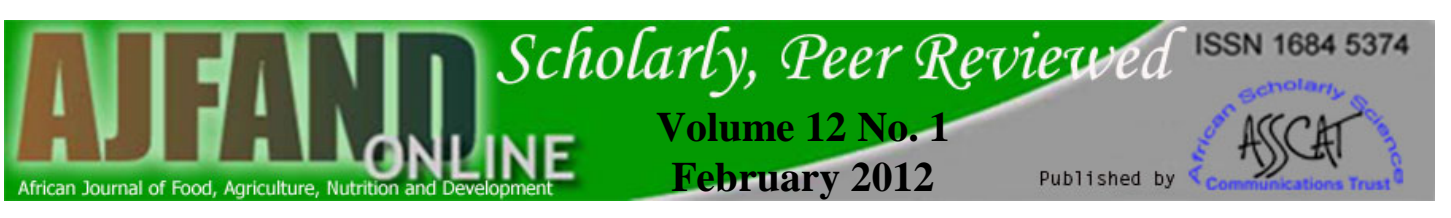

Table 5: Energy and nutrient intakes of vegetarian children from Accra and Cape Coast compared with non-vegetarian controls, based on a 12-hour home observation ${ }^{1}$

\begin{tabular}{lrrr}
\hline Nutrient & $\begin{array}{r}\text { Vegetarians } \\
(\mathbf{n}=\mathbf{1 4})\end{array}$ & $\begin{array}{r}\text { Non-vegetarians } \\
(\mathbf{n = 1 4 )}\end{array}$ & P-value $^{2}$ \\
\hline Energy (kcal) & $963.0 \pm 351.8$ & $1185.9 \pm 513.6$ & 0.190 \\
Protein (g) & $25.9 \pm 15.9$ & $33.0 \pm 17.5$ & 0.270 \\
Dietary fibre (g) & $12.1 \pm 7.3$ & $13.4 \pm 12.7$ & 0.740 \\
Thiamine (mg) & $0.9 \pm 0.6$ & $0.7 \pm 0.5$ & 0.150 \\
Riboflavin (mg) & $0.4 \pm 0.3$ & $0.6 \pm 0.4$ & 0.180 \\
Vitamin B 12 (mg) & $0.0 \pm 0.0$ & $1.1 \pm 1.2$ & \\
Vitamin A (RE) & $485.7 \pm 441.8$ & $649.3 \pm 689.7$ & 0.460 \\
Vitamin C (mg) & $55.5 \pm 43.7$ & $45.4 \pm 34.2$ & 0.500 \\
Calcium (mg) & $207.3 \pm 101.2$ & $260.5 \pm 119.9$ & 0.220 \\
Iron (mg) & $10.4 \pm 4.9$ & $10.8 \pm 5.6$ & 0.820 \\
Zinc (mg) & $3.9 \pm 1.8$ & $4.9 \pm 2.9$ & 0.290 \\
\hline${ }^{1}$ Values shown as mean \pm SD & & \\
${ }^{2}$ Differences tested with Student’s t-test & &
\end{tabular}


Table 6: Consumption of foods from the various food groups by vegetarian and non-vegetarian children from Accra and Cape Coast, based on one 24-hour recall ${ }^{1}$

\begin{tabular}{|c|c|c|c|}
\hline Food group & $\begin{array}{r}\text { Vegetarians } \\
(n=26)\end{array}$ & $\begin{array}{r}\text { Non-vegetarians } \\
(\mathrm{n}=26)\end{array}$ & P-value $^{2}$ \\
\hline Cereals & $25(96.2)$ & $26(100.0)$ & 0.313 \\
\hline Roots \& tubers & $15(57.7)$ & $16(61.5)$ & 0.777 \\
\hline Pulses \& nuts & $21(80.8)$ & $17(65.4)$ & 0.211 \\
\hline Green leafy vegetables & 15 (57.7) & $5(19.2)$ & 0.004 \\
\hline Other vegetable & $26(100.0)$ & $26(100.0)$ & - \\
\hline Fruits & $16(61.6)$ & $2(7.7)$ & $<0.001$ \\
\hline Animal source foods (ASF) & - & $23(88.5)$ & \\
\hline Fats \& oils & $25(96.2)$ & $24(92.3)$ & 0.552 \\
\hline Drinks/ beverages & $8(30.8)$ & $13(50.0)$ & 0.158 \\
\hline $\begin{array}{l}\text { Food diversity score with } \\
\text { animal source foods }{ }^{3}\end{array}$ & $5.81 \pm 0.98$ & $5.85 \pm 1.12$ & 0.830 \\
\hline $\begin{array}{l}\text { Food diversity score without } \\
\text { animal source foods } 4\end{array}$ & $5.81 \pm 0.98$ & $4.96 \pm 1.04$ & 0.540 \\
\hline $\begin{array}{l}{ }^{1} \text { Values shown as mean } \pm \text { sta } \\
{ }^{2} \text { Chi-square test was used to } \\
\text { was used to compare means } \\
{ }^{3} \text { Mean food diversity score } \mathrm{W} \\
{ }^{4} \text { Mean food diversity score d } \\
\text { food groups }\end{array}$ & $\begin{array}{l}\text { dard deviation } \\
\text { st differences b } \\
\text { h animal sourc } \\
\text { I not count anin }\end{array}$ & $\begin{array}{l}\text { r n (\%) } \\
\text { tween proportions; } \\
\text { foods; maximum o } \\
\text { al source foods; ma }\end{array}$ & $\begin{array}{l}\text { nt's t-test } \\
\text { d groups } \\
\text { of } 8\end{array}$ \\
\hline
\end{tabular}




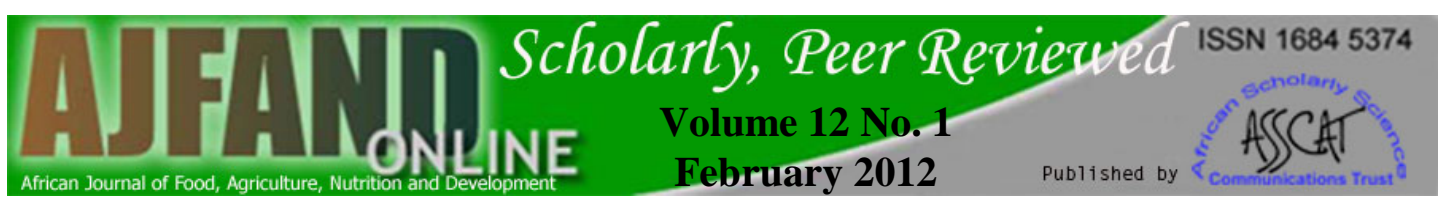

Table 7: Hemoglobin, ferritin and transferrin receptor (TfR) levels for vegetarian and non-vegetarian children from Accra and Cape Coast ${ }^{1}$

\begin{tabular}{lrrr}
\hline Variable & $\begin{array}{r}\text { Vegetarians } \\
(\mathbf{n}=\mathbf{2 6})\end{array}$ & $\begin{array}{r}\text { Non-vegetarians } \\
(\mathbf{n}=\mathbf{2 6})\end{array}$ & P-value $^{2}$ \\
\hline Hemoglobin (g/dl) & $11.8 \pm 1.1$ & $11.6 \pm 1.1$ & 0.970 \\
Plasma ferritin $(\mathrm{ng} / \mathrm{ml})$ & $34.05 \pm 25.88$ & $\begin{array}{r}59.15 \pm \\
48.18\end{array}$ & 0.012 \\
Plasma TfRconc $(\mu \mathrm{g} / \mathrm{ml})$ & $1.45 \pm 1.02$ & $1.47 \pm 0.71$ & 0.940 \\
Plasma ferritin $<15 \mathrm{ng} / \mathrm{ml}$ & $2(11.1)$ & $3(15.8)$ & 0.677 \\
IDA $^{3}$ & $1(3.8)$ & $1(3.8)$ & 1.000 \\
Anemia $^{4}$ & $6(23.1)$ & $7(26.9)$ & 0.740 \\
$\mathrm{CRP}^{\prime}>10 \mathrm{mg} / \mathrm{L}$ & $8(30.8)$ & $7(26.9)$ & 0.760 \\
\hline
\end{tabular}

${ }^{1}$ Values shown as mean \pm standard deviation or $\mathrm{n}(\%)$

${ }^{2}$ Student's t-test was used to compare means; Chi-square test was used to test differences between proportions

${ }^{3}$ IDA: Iron deficiency anemia (combination of ferritin $<15 \mathrm{ng} / \mathrm{ml}$ and $\mathrm{Hb}<11.0$ $\mathrm{g} / \mathrm{dl}$ or $11.5 \mathrm{~g} / \mathrm{dl})$

${ }^{4}$ Anemia: $\mathrm{Hb}<11.0 \mathrm{~g} / \mathrm{dl}$ for children $<5 y$ rs and $\mathrm{Hb}<11.5 \mathrm{~g} / \mathrm{dl}$ for children 5-11 y (INACG/WHO/UNICEF (1998) suggested a cut off of $\mathrm{Hb}<11.0 \mathrm{~g} / \mathrm{dl}$ for children $<5 \mathrm{y}$ and $\mathrm{Hb}<11.5 \mathrm{~g} / \mathrm{dl}$ for children 5-11 y). 


\section{REFERENCES}

1. Sanders TAB and S Reddy Vegetarian diets and children. Am. J. Clin. Nutr. 1994; 59 (suppl): 117S-81S.

2. Jacobs $\mathbf{C}$ and JT Dwyer Vegetarian children: appropriate and inappropriate diets. Am. J. Clin. Nutr. 1988; 48: 811-818.

3. Dwyer JT, Dietz WHbJr, Andrews EM and RM Suskind Nutritional status of vegetarian children. Am. J. Clin. Nutr. 1982; 35: 204-216.

4. Dagnelie PC, van Staveren WA, Verschuren SA and JG Hautvast Nutritional status of infants aged 4 to 18 months on macrobiotic diets and matched omnivorous control infants: a population-based mixed-longitudinal study II. Growth and psychomotor development. Eur. J. Clin. Nutr. 1989; 43: 325-338.

5. Key TJ, Appleby PN and MS Rosell Health effects of vegetarian and vegan diet. Proc. Nutr. Soc. 2006; 65: 35-41.

6. World Health Organization Malnutrition, The global picture. Geneva: World Health Organization, 2000.

7. Gibson RS, Ferguson EL and $\mathbf{J}$ Lehrfeld Complementary foods for infant feeding in developing countries: their nutrient adequacy and improvement. Eur. J. Clin. Nutr. 1998; 52: 764-770.

8. Armstrong BK, Davis RE, Nicol DJ, van Merwyk AJ and CJ Larnwood Hematological, vitamin $\mathrm{B}_{12}$ and folate studies on Seventh-day Adventist vegetarians. Am. J. Clin. Nutr. 1974; 27: 712-718.

9. Stabler SP and RH Allen Vitamin B12 deficiency as a worldwide problem. Ann Rev Nutr. 2004; 24: 299-326.

10. Herbert V Vitamin $\mathrm{B}_{12}$ : plant sources, requirements and assay. Am. J. Clin. Nutr. 1998; 48: 852-858.

11. Dagnelie PC, van Staveren $\mathbf{W A}$ and $\mathbf{H}$ van den Berg Vitamin $B_{12}$ from algae appears not to be bioavailable. Am. J. Clin. Nutr. 1991; 53: 695-697.

12. Dwyer JT, Andrew EM, Berkey C, Valadian I and RB Reed Growth in "new" vegetarian preschool children using the Jenss-Bayley curve fitting technique. Am .J. Clin. Nutr. 1983; 37: 815-827.

13. Israel AB Renew your strength and prevent disease: The Dimona System. Health foresight-Ministry of Health, Ghana, 2007; pp 13-14 
14. Nathan I, Hackett AF and A Kirby Dietary intake of a group of vegetarian children aged 7-11 years compared with matched omnivores. Br. J. Nutr. 1996; 75: 533-544.

15. WHO Multicentre growth Reference Study Group WHO Child Growth Standards based on length/height, weight and age. Acta. Paediatr. Suppl. 2006; 450: 76-85.

16. Eyeson K, Ankrah EK, Sundararajan AR, Karinpaa A, and JM Rudzka Composition of foods commonly used in Ghana. Accra, Ghana: Food Research Institute. Council for Scientific and Industrial Research, 1975.

17. Ferguson EL, Gibson RS, Opare-Obisaw C, Osei-Opare F, Srephen AM, Lehrfeld $\mathbf{J}$ and LU Thompson The zinc, calcium, copper, manganese, nonstarch polysaccharide and phytates content of seventy-eight locally grown and prepared African foods. J. Food Comp. Anal. 1993; 6: 87-99.

18. Savy M, Martin-Prevel Y, Sawadogo P, Kameli Y and F Delpeuch Use of variety/ diversity scores for diet quality measurement: relation with nutritional status of women in a rural area in Burkina Faso. Eur. J. Clin. Nutr. 2005; 59: 703-716.

19. Stoltzfus RJ and ML Dreyfus Guidelines for the use of iron supplements to prevent and treat iron deficiency anemia: International Nutritional Anemia Consultative Group (INACG), World Health Organisation (WHO), United Nations Children's Fund (UNICEF). International Life Sciences Institute Press, Washington, 1998.

20. WHO Child growth standards SAS macro. Geneva: WHO, 2006. Available from: http://www.who.int/childgrowth/software/readme_sas.pdf. (Accessed March, 2009)

21. de Onis M, Onyango A, Borghi E, Siyam A, Nishida C and J Siekmann Development of a WHO growth reference for school-aged children and adolescents. WHO Bull. 2007; 85: 661-668.

22. Lacroix J, Machter MA, Badoual $\mathbf{J}$ and $\mathbf{G}$ Huault Complications of a vegetarian diet in a breast-fed girl. Arch Fr. Pediatr. 1981; 38: 233-238.

23. Sklar R Nutritional vitamin B-12 deficiency in a breast-fed infant of a vegandiet mother. Clin. Pediatr. 1986; 25: 219-221

24. Higginbottom MC, Sweetman $\mathbf{L}$ and $\mathbf{W L}$ Nyhan A syndrome of methyl malonicaciduria, homocysteinuria, megaloblastic anaemia and neurological abnormalities in vitamin $\mathrm{B}_{12}$ deficient breast-fed infant of a strict vegetarian. N. Engl. J. Med. 1978; 299: 317-323. 
25. Marquis GS, Colecraft E, Sakyi-Dawson O, Lartey A, Ahunu B, Butler LM, Reddy M, Jenson H, Lonergan E and R Aryeetey Animal source food intake is higher in child-level secure households. Ecol. Food Nutr. 2006; 45:351-377.

26. Brown KH Effect of infections on plasma zinc concentrations and implications for zinc status assessment in low-income countries. Am J. Clin. Nutr. 1998;68: 425S-429S.

27. Gibson RS. Assessment of iron status. In: Principles of nutritional assessment. $2^{\text {nd }}$ ed. Oxford university press, Oxford. 2005: 443-471.

28. Waldmann A, Koschizke JW, Leitzmann C and A Hahn Dietary iron intake and iron status of German female vegans: results of the German vegan study. Ann. Nutr. Metabol. 2004; 48: 103-108.

29. Commey JO and P Dekyem Childhood deaths from anaemia in Accra, Ghana. West African J. Med. 1995; 14: 101-104.

30. Ronnenburg AG, Goldman MB, Aitken IW and $\mathbf{X} \mathbf{X u}$ Anemia and deficiencies of folate and vitamin B-6 are common and vary with season in Chinese women of childbearing age. J. Nutr. 2000; 130: 2703-2710.

31. Kapur D, Agarwal KN and DK Agarwal Nutritional anaemia and its control. Indian J. Pediatr. 2002; 69: 607-616. 